\title{
Algunas peculiaridades en el lenguaje japonés
}

\section{I} ntroducción

Dicen que el idioma japonés es uno de los más difíciles de aprender. No es por cuestión fonética, sino por su escritura y variación sociocultural. Los hispanohablantes no tendrán tanta dificultad, ya que ambos idiomas son silábicos y tienen cinco vocales $(a, e, i, o, u)$. En este sentido existen ciertas semejanzas entre ellos. Citamos algunas palabras: kasa 'paraguas', ame 'lluvia', koma 'trompo', kuchí 'boca', mimí 'orejas', etcétera. Con las consonantes debemos tener más cuidado. Por ejemplo, 'Pedro' se pronunciaría en nuestro idioma como Pedoro, ya que en japonés no hay consonantes dobles, mucho menos triples.

La escritura japonesa es más compleja. Tiene dos tipos de alfabetos: hiragana $\mathrm{y}$ katakana, con 46 letras cada uno. El primero se usa normalmente como palabra o partícula, mientras que el segundo para extranjerismos $\mathrm{y}$, a veces, para cuando quiere enfatizarse la acción de una persona o el estado de un objeto. Además, los japoneses deben aprender por lo menos de tres a cuatro mil caracteres chinos (kanji) que acompañados del hiragana son utilizados para referirse al verbo, al sustantivo y al calificativo. Lo más sorprendente es que estos kanjis tienen dos o más formas de pronunciación que depende de su combinación. Así que ya podrán imaginarse la dificultad para dominar esta lengua.

Otra complicación es su variación sociolingüística. Los japoneses aprendemos en la escuela el llamado "japonés estándar", que corresponde, en mayor o menor grado, al lenguaje formal utilizado en la sociedad. Sin embargo, en casa hablamos de manera familiar o informal. Por ejemplo, una expresión común ¿tabemasu ka? ‘come usted?' se convierte en

* Investigador del Departamento de Estudios del Pacífico de la Universidad de Guadalajara. ¿taberu? ('¿comes?') en el habla familiar. En las oficinas, sobre todo cuando alguien se dirige a un superior o a un cliente, no basta con la forma común, ya que ahí tienen que usarse formas más reverenciales, como ¿o-tabeni-narimasu $k a$ ? o meshiagarimasu ka?, que en español sería: ‘¿le gustaría comer?'.

El propósito de este escrito es que el lector tenga una idea general del idioma, por medio de algunas expresiones usuales de la vida cotidiana en Japón. El análisis será lingüístico y cultural, ya que como dice E. Sapir ${ }^{1}$, el lenguaje y la cultura están estrechamente vinculados. Nos parecería demasiado complicado aprenderlo sólo con gramática, pues una de sus principales características es su "ambigüedad", concepto que apenas podría entenderse al conocer su misteriosa cultura.

\section{Significado de algunos saludos básicos}

\section{[arigatou / ohayou / kon'nichiwa / konbanwa]}

El enunciado arigatou tiene significado de agradecimiento, como 'gracias' en español. Ese término puede oírse en cualquier lugar y en diversas situaciones sociales, como en la familia, entre los amigos o compañeros del trabajo e, incluso, cuando alguien se dirige a otra persona de menor edad. Sin embargo, un empleado japonés no se atrevería a decirle arigatou a su jefe, sino utilizaría otra forma más reverencial, como arigatou-gozaimasu ('muchas gracias').

Otro detalle. Si alguien invita a cenar a un japonés, les podría decir al día siguiente: kinou wa arigatou-gozaimashita ('muchas gracias por lo de ayer'). Puede observarse que existen diferencias en la terminación del vocablo. Es decir, esta terminación mashita se 
refiere a una acción pasada, en cambio masu habla de algo que sucede en el presente o que ocurrirá en el futuro. En este caso, el invitado expresa su agradecimiento por la invitación.

Arigatou proviene de arigatashi, que significa 'es imposible' o 'que no puede ser'. Cuando sucedía un milagro, se supone que la gente daba las gracias a los dioses ${ }^{2}$ o budas y decían que "no puede ser; es un milagro; muchísimas gracias".

En Japón, el saludo ohayou significa 'buenos días'. Esta expresión es común en la familia y entre amigos; en cambio, en el lenguaje formal hay que decir ohayougozaimasu ('muy buenos días'), el mismo caso de larigatou/ - larigatou-gozaimasu/. Es interesante observar que a veces se oye ohayou-gozaimashita, en especial en la gente mayor, pero este uso debe considerarse erróneo porque no se refiere a un hecho del pasado, sino a un acción que está realizándose en el momento.

En algunas situaciones, por ejemplo, entre artistas o en empresas como SevenEleven que funcionan las veinticuatro horas, se acostumbra saludar ohayou-gozaimasu en la tarde e, incluso, en la noche. Este uso quizá sea más correcto desde el punto de vista etimológico, pues la frase ohayou originalmente significaba 'ya que usted se ha levantado temprano, debe estar bien de salud ¡qué bueno!'. Por esta razón no importaba la hora y era usado para felicitar a una persona o animarla.

A partir del mediodía, hasta antes de oscurecer (probablemente hasta las cinco de la tarde) se usa kon 'nichiwa ('buenas tardes'), ya que etimológicamente significa 'hoy es buen día, ¿verdad?'. Puede oírse en algunas ocasiones durante todo el día, excepto en la noche. Este saludo correspondería a 'ihola!' en español.

Después de las cinco de la tarde puede decirse konbanwa, frase cuyo significado original era 'esta noche es muy buena'.

Correspondería a la expresión "buenas noches", puesto que konbanwa se utiliza únicamente como saludo de encuentro nocturno o vespertino tardío, pero nunca para desear a alguien que duerma bien. ${ }^{3}$ Estas últimas expresiones kon nichiwa y konbanwa están tan generalizadas en el lenguaje japonés, que son comunes en cualquier ambiente.

\section{Algunas expresiones ambiguas}

[sumimasen] Una de las expresiones más usuales en Japón es sumimasen, que tiene tres valores semánticos: 'agradecimiento', 'disculpa' y 'llamamiento'. Cuando alguien da las gracias a otra persona puede decirle sumimasen, de la misma manera quearigatou. La misma voz, sin embargo, puede usarse para pedir disculpas. Supongamos que alguien pisa el pie de una persona, le diría de inmediato sumimasen o gomen-nasai ('perdón' o 'discúlpeme').

Literalmente sumimasen se refiere a que 'no ha terminado la acción'. Haga, Sasaki y Kadokura $^{4}$ señalan que al recibir un favor, uno no siempre puede regresárselo y se siente apenado por no poder cumplir con su comportamiento. De ahí que tenga significado de 'perdón'.

Para preguntar algo podemos decir sumimasen, que corresponderá a la expresión "perdón" o "disculpe". También puede anteponerse chotto a la mima expresión. Por ejemplo, chotto sumimasen, eki wa doko desu $k a$ ? ('Disculpe, ¿dónde está la estación?'), pero no altera su significado.

[Yoroshiku onegai-shimasu] La primera parte de la frase: yoroshiku significaba en la antigüedad 'más o menos' o 'de alguna manera u otra'. En la actualidad tiene valor de 'moderación'. Esa expresión es usada cuando uno espera que otra persona le haga un favor, pero con prudencia. Así es que no es un favor forzoso. Veamos el siguiente diálogo. 
A Hajimemashite. Yoroshiku onegai-shimasu. ('Mucho gusto. Le voy a pedir favores...')

B Kochira koso. ('Al contrario. El gusto es mío.')

Esta expresión es muy común en Japón para presentarse ante otra persona, y puede oírse con frecuencia en el trabajo, en la escuela y casi en cualquier situación social. En este caso, el que se presenta tiene la idea o la esperanza (una especie de halago psicológico) para que la otra persona en el futuro le haga algún favor.

Para entender esta situación bastaría otro ejemplo: Shigoto no koto, yoroshiku onegai-shimasu ('Le voy a encargar lo del trabajo y espero recibir el favor.'). Si un japonés va con algún conocido para pedirle un trabajo, con seguridad le dirigiría este término al despedirse. Esta frase tiene una connotación de 'cierta esperanza' de que le consiga trabajo. Lo interesante es que la persona que lo recibió no necesariamente le buscará un empleo. Todo dependerá del carácter de esa persona. En este caso, entre el emisor y el receptor se presenta una confusión o ambigüedad comunicativa. En otras palabras, en Japón el uso de este tipo de expresiones sirve como lubricante, pues por lo general es mal visto expresar sentimientos de manera directa.

[chotto] El adverbio chotto significa 'un poco', al igual que sukoshi, pero se usa en general para expresiones familiares o coloquiales, ya que el último tiene un uso más formal. Estos dos adverbios pueden referirse a 'tiempo', 'cantidad de un objeto' y 'grado de intensidad'. Citaremos un ejemplo:
Lenguaje familiar: chotto matte ('espera un momento').

Lenguaje formal: sukoshi matte-kudasai ('espere un momento').

Según algunos investigadores, ${ }^{5}$ esta expresión puede tener hasta cinco usos. Presentaremos dos que nos parecen más usuales e interesantes para el lector extranjero. Para llamar la atención a una persona se le dice chotto sumimasen ('disculpe...'; 'oiga...'; 'perdón...'). Por supuesto, como hemos visto podemos utilizar una sola forma: sumimasen. Es también aceptable el uso simplificado de la expresión: chotto. En este caso podrá considerarse que hubo una omisión sintáctica de la última parte de la frase.

Cuando esta palabra va al final de la frase, por lo general se trata de una idea negativa. Lo explicaremos con el siguiente diálogo

A Kaeri ni ippai dou desu ka? (“Qué tal si tomamos una copita al regreso?')

B Sumimasen. Kyou wa chotto... ('Lo siento. Pues...hoy no...')

En este caso, la idea que tiene el hablante $B$ es negativa, ya que puede suponerse que hubo omisión de la locución verbal en negativo: ike-masen ('no poder ir') o tal vez tsukiae-masen ('no poder acompañarle'). Si dijéramos chotto ike-masen, aunque gramaticalmente es correcto, sonaría hasta cierto punto chocante o, más bien, demasiado seco. La connotación semántica es común en el lenguaje japonés, lo cual facilita suavizar las relaciones humanas para evitar discusiones o choques psicológicos. 
A un extranjero le parecería incluso ilógica esta conducta, pero para vivir en Japón armoniosamente con los amigos, con los vecinos, con los compañeros del trabajo y, a fin de cuentas, con todos los demás, se recomienda aprender esta ideología.

[sorosoro] Esta locución japonesa tiene una connotación similar al caso dechotto. Basta con citar un ejemplo. Supongamos que estamos de visita en casa de algún amigo. Después de pasar un rato, cuando creemos que ya es la hora de irnos, acostumbramos decir al anfitriónjaa sorosoro, que en este caso significaría 'bueno, entonces...ya nos vamos'. Esta es una expresión indirecta y suave.

Sorosoro ${ }^{6}$ es por sí solo un adverbio con valor de 'inicio de algún movimiento lento o gradual'; jaa se considerará como conjunción española 'bueno' o 'entonces'. De modo que sorosoro nunca significa 'irse'. A pesar de su propio significado y de su estructura superficial sintáctica, esta palabra puede ser connotativa, por lo tanto podrá referirse a casi toda clase de movimientos como 'salir de casa', 'acostarse', 'comer', 'estudiar' y otros. A propósito, la mayor diferencia que hay entre sorosoro y chotto la podremos encontrar en el concepto de la dicotomía: afirmación y negación.

\section{Conclusión}

El idioma japonés es considerado como misterioso, al igual que su país. Después de nuestras pequeñas observaciones es indudable que se debe a la diversidad de los usos en el contexto social, aunque excluyamos en este caso cuestiones dialectales. Por otra parte, hemos visto también que la ambigüedad semántica es uno de los factores que tal vez causen dificultad a los estudiosos del japonés. En particular, la connotación semántica es la que está íntimamente vinculada con la cultura japonesa. Sin ningún conocimiento sobre Japón y su cultura costaría mucho trabajo entender este idioma. Ni hablar si usted quiere dominarlo.

\section{Notas}

1 Language: An Introduction to the Study of Speech, New York, Harcout, Brace. 1921.

2 El catolicismo es monoteísta , mientras que en Japón tanto el sintoísmo como el budismo son politeístas. Así que tranquilamente se puede combinar una religión con otra.

3 Como saludo de despedida, antes de acostarse, utilizamos oyasumi u oyasumi-nasai que significarían en español 'que descanse (s) bien'.

4 Aimaigo-jiten (Diccionario de palabras ambiguas). Tokio, Tokio-do Shuppan, 1996. pp.131-132.

5 Haga, Sasaki y Kadokura, op. cit. pp.171-172.

6 En el japonés existen muchos adverbios con reiteración silábica: dandan ('poco a poco'), zaazaa ('a cántaros'), pikapika-ni ('brillosamente'), etcétera. 